\title{
GCU
}

Glasgow Caledonian

University

University for the Common Good

\section{Social participation and heat-related behavior in older adults during heat waves and on other days}

Lindemann, Uli; Skelton, Dawn A.; Oksa, Juha; Beyer, Nina; Rapp, Kilian; Becker, Clemens;

Klenk, Jochen

Published in:

Zeitschrift für Gerontologie und Geriatrie

DOI:

10.1007/s00391-017-1338-8

Publication date:

2018

Document Version

Author accepted manuscript

Link to publication in ResearchOnline

Citation for published version (Harvard):

Lindemann, U, Skelton, DA, Oksa, J, Beyer, N, Rapp, K, Becker, C \& Klenk, J 2018, 'Social participation and

heat-related behavior in older adults during heat waves and on other days', Zeitschrift für Gerontologie und

Geriatrie, vol. 51, no. 5, pp. 543-549. https://doi.org/10.1007/s00391-017-1338-8

\section{General rights}

Copyright and moral rights for the publications made accessible in the public portal are retained by the authors and/or other copyright owners and it is a condition of accessing publications that users recognise and abide by the legal requirements associated with these rights.

Take down policy

If you believe that this document breaches copyright please view our takedown policy at https://edshare.gcu.ac.uk/id/eprint/5179 for details

of how to contact us. 


\section{Effect of Indoor Temperature on Social Life Participation and Behavior in Older Adults}

during Normal Days and Heat waves

Ulrich Lindemann ${ }^{1,}$, , Dawn A. Skelton ${ }^{2}$, Juha Oksa ${ }^{3}$, Nina Beyer ${ }^{4}$, Kilian Rapp $^{1,5}$, Clemens Becker ${ }^{1,}$, Jochen Klenk ${ }^{1,5}$

\section{Affiliations}

${ }^{1}$ Department of Clinical Gerontology and Rehabilitation, Robert-Bosch-Hospital, 70376

Stuttgart, Germany, Academic Center at the University of Tuebingen, 72074 Tuebingen, Germany; E-Mails: ulrich.lindemann@rbk.de (UL), jochen.klenk@rbk.de (JK); clemens.becker@rbk.de (CB); kilian.rapp@rbk.de (KR)

${ }^{2}$ Institute of Applied Health Research, Glasgow Caledonian University, Scotland, G4 0BA, UK; E-Mail: dawn.skelton@gcu.ac.uk

${ }^{3}$ Quantified Employee, Finnish Institute of Occupational Health, 90220 Oulu, Finland; E-Mail: juha.oksa@ttl.fi

${ }^{4}$ Musculoskeletal Rehabilitation Research Unit, Bispebjerg and Frederiksberg Hospitals, University of Copenhagen, 2400 NV Copenhagen, Denmark; E-Mail:

ninabeyer.privat@gmail.com

${ }^{5}$ Institute of Epidemiology and Medical Biometry, Ulm University, 89081 Ulm, Germany

* Author to whom correspondence should be addressed; E-Mail: ulrich.lindemann@rbk.de 
Abstract: High indoor temperature requires behavioral adaptation. The aim of this study was to describe the association between indoor temperature and social participation and heatrelated behavioral adaptation in older adults. Eighty-one older adults ( $84 \%$ women, mean age 80.9 years, SD 6.53) were visited every 4 weeks from May to October 2015 and additionally during 2 heat waves in July and August 2015. Indoor temperature, drinking and clothing and social life participation were assessed. Baseline assessment of gait speed and residential area were used to create sub-groups of people with higher versus lower gait speed and living in garden-city/suburb versus city/city-center, respectively. Participation and clothing decreased (-4.53 WHO participation score units; $95 \%-\mathrm{Cl}-5.32$; -3.74 and -0.41 clounits; $95 \%-\mathrm{Cl}-0.46 ;-0.37$, respectively) and volume of drinking increased $(0.65$ liter; $95 \%-\mathrm{Cl}$ $0.52 ; 0.77$ ) per $10^{\circ} \mathrm{C}$ increasing indoor temperature in the total group. The decrease of social life participation per $10^{\circ} \mathrm{C}$ increase of indoor temperature was higher in those living in the city/city-center $(-5.87$ score units; $95 \%-\mathrm{Cl}-7.01 ;-4.73)$ compared to those living in a gardencity/suburb (-3.11 score units; 95\%-Cl -4.19; -2.03). Temperature-related adaptive behavior was not documented in all adults, especially during a heat wave. With regard to heat-related adaptation of drinking and clothing during heat, external attention and care might be necessary.

Keywords: adaptation; heat-related behavior; indoor temperature; older adults; social participation 


\section{Introduction}

Heat waves with extreme temperatures in summer are associated with increased mortality, especially among vulnerable older adults (Baccini, Kosatsky, \& Biggeri, 2013; Kaiser et al., 2007; Klenk, Becker, \& Rapp, 2010; Sun et al., 2014; Tong, Ren, \& Becker, 2010). In general, there are uncertainties to which degree people adapt to these challenging conditions (Wardekker, de, van, Turkenburg, \& van der Sluijs, 2012).

Indoor temperature seems to be relevant with regard to heat-related self-perceived health problems (van Loenhout et al., 2015) and changes in physiological parameters, e.g. in blood pressure (Barnett et al., 2007). This is comprehensible in an older population that spends much of its time indoors. While autonomic thermoregulations, such as changes in blood pressure or sweating, are rather driven by heat sensation, temperature-related behavioral adaptations are rather driven by discomfort (Flouris, 2011). In this context it is worth mentioning that the sensitivity of older adults to changes in environmental temperature conditions is diminished (Collins \& Exton-Smith, 1983).

Restrictions in social life participation are described for cold weather conditions especially in older adults (Clarke, Yan, Keusch, \& Gallagher, 2015). Furthermore, weather conditions affect physical activity of older adults (Klenk, Buchele, Rapp, Franke, \& Peter, 2012). Both studies report effects of outdoor temperature conditions. At present there is no study describing the effect of high indoor temperature on social participation of older adults.

General recommendations how to adapt to high environmental temperature, such as light clothing and more drinking, are qualitatively reported (yes/no) (Liu et al., 2013), but not the amount of temperature-related behavioral adaptation, such as the volume of drinking. A study recording the frequency of temperature -related adaptations (yes/no per time) reported an underuse of heat-protective behavior in older adults (White-Newsome et al., 2011). Not only understanding the association between temperature and qualitative adaptation, but also 
knowledge about the quantity of this adaptation is necessary for recommendations on how to adapt behavioral strategies at times of heat stress.

Besides physiological factors such as frailty, which is one aspect to describe the vulnerability of older adults (Fried et al., 2001), environmental factors such as the residential area are discussed as a possible effect modifier of heat stress. The accessibility to green spaces is associated with better perceived general health (Maas, Verheij, Groenewegen, de Vries, \& Spreeuwenberg, 2006) and reduced heat-related mortality (Burkart et al., 2016).

Furthermore, the urban heat island effect has been shown to increase heat-related mortality (Tan et al., 2010).

The aim of this study was to describe the association between indoor temperature and social life participation and temperature -related behavior of older adults during normal days and heat waves in a country where air conditioning is not common. Furthermore, possible effect modifiers were investigated.

\section{Methods}

\subsection{Subjects and design}

For this panel study with repetitive measurements, a convenience sample of independent older adults was recruited in 10 facilities of sheltered living in one city in Southern Germany. Inclusion criteria were an age of 60 years and older, no need of formal or informal support and a regular outdoor activity of at least 30 minutes per day. Exclusion criteria were not being able to follow instructions, uncontrolled cardiac illness, use of a wheel chair and terminal illness. All subjects gave their written informed consent for inclusion before they participated in the study. The study was conducted in accordance with the Declaration of Helsinki, and the protocol was approved by the ethical committee of the University of Tuebingen (080/2015/BO2). 


\subsection{Assessment protocol}

Starting in May 2015 and ending in October 2015 the participants were visited every 4 weeks. Additional assessments were conducted during 2 heat waves in July and August with a heat wave defined as 3 or more consecutive days with maximum temperatures of $30^{\circ} \mathrm{C}$ or more and a heat alarm from the German Meteorological Service. Thus, a maximum of 8 assessments were conducted per participant. The duration of one visit was approximately 30 minutes. All assessments were performed between 8 AM and 3 PM visiting each participant individually at the same time of the day. After the heat waves the participants' heat-protective behavior in general was recorded.

\subsection{Repetitive assessment}

\subsubsection{Climate condition:}

Maximum indoor temperature and humidity were measured during the assessment with a data logger (HL-1D, ROTRONIC Messgeräte GmbH, Ettlingen, Germany), which was placed on a table in the shade in the room where the assessment was conducted. Since there was hardly any change of temperature and humidity (maximum $1^{\circ} \mathrm{C}$ and $1 \%$, respectively) during the assessment, the maximum values were used and a heat-index (Steadman, R.G., 1979) was calculated, which combines air temperature and relative humidity, in shaded areas, as an attempt to determine the human-perceived equivalent temperature.

\subsubsection{Heat-related behavior}

The volume of drinking [l] of the previous day was asked in a standardized interview adding all consecutive drinks of the previous day.

Clothing of the participants during the assessment was described by the sum value of "clo units" (ISO 9920, n.d.) in order to reflect the behavioral adaptation of thermal insulation to the 
indoor climate condition (Pascoe, Shanley, \& Smith, 1994). Each item of clothing was referred by a numerical score (e.g. 0.02 for light socks or 0.25 for a long-sleved shirt).

\subsubsection{Social life participation}

Participation in social life was assessed using a sub-scale (questions $40,42-44$ ) of the WHOQoL questionnaire (Power, Quinn, \& Schmidt, 2005). The 4 questions focusing on 1) general activity, 2) how to spend time, 3) the amount of activity and 4) participation in the community were modified in order to link social life participation to actual temperatures (e.g. "How satisfied are you at these temperatures with the opportunity to participate in the community?"). Answers were given on a 5-point Likert-scale ( 1 = very unsatisfied; 5 = very satisfied). The sum-score of the 4 questions (best score $=20$; worst score $=4$ ) was used for analysis.

\subsection{Descriptive measures and self-report of heat protective behavior}

Age, body weight and body height were recorded at the first visit and the body mass index was calculated.

Co-morbidity was assessed via a standardized questionnaire asking for 18 age-relevant diseases and symptoms (Groll, To, Bombardier, \& Wright, 2005). Yes/no answers resulted in a maximum (worst) score of 18 .

In order to describe the functional status of participants and to create sub-groups for analyses, habitual gait speed [m/s] was measured using a stopwatch over a distance of 4 meters at the first visit/assessment at a mean indoor temperature of $22.7^{\circ} \mathrm{C}$. If needed, assistive devices could be used. According to Fried et al. (Fried et al., 2001), the gender specific cut-offs for low gait speed were $0.653 \mathrm{~m} / \mathrm{s}$ or slower for women and men with body height less than $159 \mathrm{~cm}$ and $173 \mathrm{~cm}$, respectively, and $0.762 \mathrm{~m} / \mathrm{s}$ or slower for women and men with body height of at least $159 \mathrm{~cm}$ and $173 \mathrm{~cm}$, respectively. The rationale to use gait speed was because it is highly correlated with frailty (Schoon, Bongers, Van Kempen, Melis, 
\& Olde Rikkert, 2014; Schwenk et al., 2014). Furthermore, it has high face-validity and is the only frailty criterion to be assessed objectively with a ubiquitous tool (stop watch).

Cognition was screened by the Short Orientation Memory Concentration test (Katzman et al., 1983 ) with weighted scores of 0 (best) to 28 (worst) and a score of $>10$ suggesting cognitive impairment.

The residential area of the facilities of sheltered living was dichotomized in gardencity/suburb or city/city-center, which was based on the real land use map of the city (“Stadtklima Stuttgart | Klimatope | 9. Klimaanalyse-Karten (Karte-XIII, Blatt 1 bis 12)," n.d.). In a structured interview after the heat waves the participating adults were asked if the summer heat was perceived as stressful this year. Answers were given on a 5-point Likertscale $(1=$ not at all; $5=$ extremely). Furthermore, they were asked (yes/no) if they had adapted their behavior to the heat by drinking more, light clothing or reduction of activity. Other heat-protective behavior was asked for with free answers.

\subsection{Statistics}

The association between indoor temperature and behavior was modeled using multilevel additive models in order to account for the time series nature of the data. The models were set up to describe individual effects using random intercepts, where visits at different time points (level 1) were nested within persons (level 2). To consider the correlation of repeated measurements, an unstructured covariance matrix was used. Spline terms were included as fixed effects to illustrate the shape of the association between indoor temperature and behavior. To reduce the effect of extreme values on the margins of the distribution, $2.5 \%$ of the observations on each margin were excluded in the figures. Measured and unmeasured covariates on the individual level which are stable over the observation period (e.g. sex and education) are inherently controlled by the multilevel structure of the model. Multi-level linear regression models were also used to calculate the slope between indoor temperature and the considered behavior measures as well as to estimate the differences 
between days within and outside heat waves. Heat wave (within and outside) was treated as a dichotomous variable. Analyses were additionally stratified by gait speed and/or residential area to assess possible effect modification. Spline figures were modeled using $R(R$ Foundation for Statistical Computing, Vienna, Austria) version 3.3.1 and the mgcv package version 1.8-17 for mixed GAM computation. All other analyses were conducted using SAS version 9.4 software (SAS Inc., Cary, USA).

\section{Results}

Eighty-one older adults with a mean age of 80.9 years (68 women, $84 \%$ ) were included. A total of 540 visits/assessments were conducted with a mean of 6.7 visits/assessments per participant. One-hundred-twelve of these visits (mean 1.6 per participant) were conducted during the two heat waves in July and August. All missing visits were due to participants having other engagements. No visit was cancelled due to perceived heat-stress. The minimum indoor temperature of all visits was $17.2^{\circ} \mathrm{C}$ on October $14^{\text {th }}$, the maximum indoor temperature was $30.3^{\circ} \mathrm{C}$ on July $7^{\text {th }}$. During the assessment period 1 participant died after the $5^{\text {th }}$ visit and 1 participant moved to a nursing home after the $4^{\text {th }}$ visit. A description of the cohort in detail is shown in Table 1.

Categorizing the participants according to gait speed and residential area, sub-groups of 34 adults with initially low gait speed versus 47 adults with initially high gait speed and 37 participants living in a garden-city/suburb versus 44 participants living in the city/city-center were created. 
Table 1: Baseline characteristics of all participating older adults at first assessment in May at a mean indoor temperature of $22.7^{\circ} \mathrm{C}$

\begin{tabular}{|c|c|c|c|}
\hline & \multirow[b]{2}{*}{ Total $(n=81)$} & \multicolumn{2}{|c|}{ Habitual gait speed } \\
\hline & & $\operatorname{Low}^{*}(n=34)$ & $\operatorname{High}^{*}(n=47)$ \\
\hline Female, n (\%) & $68(84)$ & $29(85)$ & $39(83)$ \\
\hline Age [years], mean (SD) & $80.9(6.53)$ & $81.7(7.40)$ & $80.4(5.85)$ \\
\hline Body height [cm], mean (SD) & $158.7(8.13)$ & $157.2(8.74)$ & $159.7(7.61)$ \\
\hline Body-Mass-Index [kg/m²], mean (SD) & $27.9(4.75)$ & $28.4(5.08)$ & $27.6(4.54)$ \\
\hline SOMC [ㅁ-28], mean (SD) & $3.51(3.17)$ & $3.32(2.56)$ & $3.63(3.55)$ \\
\hline Co-morbidity [ㅁ-18], mean (SD) & $4.15(2.33)$ & $5.12(2.04)$ & $3.47(2.30)$ \\
\hline Drugs [n], mean (SD) & $4.85(3.45)$ & $6.03(3.52)$ & $4.00(3.16)$ \\
\hline Habitual gait speed [m/s], mean (SD) & $0.74(0.26)$ & $0.51(0.12)$ & $0.91(0.20)$ \\
\hline $\begin{array}{l}\text { WHO participation score [4-20], mean } \\
\text { (SD) }\end{array}$ & $16.9(2.59)$ & $15.8(2.69)$ & $17.7(2.26)$ \\
\hline $\begin{array}{l}\text { Amount of drinking per day [I per day], } \\
\text { mean (SD) }\end{array}$ & $1.67(0.52)$ & $1.69(0.53)$ & $1.66(0.51)$ \\
\hline Clothing [CloUnits], mean (SD) & $0.56(0.18)$ & $0.54(0.18)$ & $0.56(0.18)$ \\
\hline Total number of measurements, $n$ & 540 & 216 & 324 \\
\hline $\begin{array}{l}\text { Total number of measurements during } \\
\text { heat waves, } \mathrm{n}\end{array}$ & 112 & 44 & 68 \\
\hline
\end{tabular}

* Frailty criteria for gait speed, i.e. low gait speed: $0.653 \mathrm{~m} / \mathrm{s}$ or slower for women $/ \mathrm{men}$ with body height $<159 / 173 \mathrm{~cm}$, and $0.762 \mathrm{~m} / \mathrm{s}$ or slower for women/men with body height $\geq 159 / 173 \mathrm{~cm}$; SOMC = Short Orientation Memory Concentration test; better score values are underlined

Multi-level linear regression analysis revealed a negative effect of increasing indoor temperature on social life participation in all groups (Figure $1 \mathrm{~A}$ ). Social life participation was higher in adults with high gait speed than in adults with low gait speed at all temperatures (Table 2). The effect per $10^{\circ}$ increase of indoor temperature was strongest in adults with initially low gait speed (-5.76; Cl 95\% -7.13; -4.39). Stratification for residential area showed a stronger decrease of social participation in those living in the city/city center at temperatures higher than $25^{\circ} \mathrm{C}$ (Figure $1 \mathrm{~B}$ ), leading to a decrease of $-5.87(\mathrm{Cl} 95 \%-7.01$; 4.73) per $10^{\circ} \mathrm{C}$ (Table 2). Comparing results from assessments in absence of a heat wave to 
results assessed during a heat wave, again the highest decrease of participation during a heat wave was seen in adults with initially low gait speed and in those living in the city/city center (-3.43; CI 95\% -4.26; -2.60 and -3.33; CI 95\% -3.99; -2.67, respectively). In general, similar patterns were observed for the heat index compared to results of maximum indoor temperature for all outcomes. Therefore, the results related to the heat index are not presented here and in the following because of the better usability of maximum indoor temperature.

The standardized interview asking for all drinks of the previous day was well adopted by the participants resulting in self-managed drink-protocols. Volume of drinking increased with increasing indoor temperature in the total group and the sub-group of those with initially low gait speed nearly linearly whereas in the sub-group of those with initially high gait speed a nearly linear increase was seen only at higher temperatures (Figure 2A). Table 2 shows the highest increase per $10^{\circ} \mathrm{C}$ in adults with initially low gait speed $(0.71 \mathrm{I} ; \mathrm{Cl} 95 \% 0.49 \mathrm{I} ; 0.93 \mathrm{I})$. However, comparing results from assessments in absentia of a heat wave to results assessed during a heat wave the volume of drinking was lowest in this group of older adults (0.27 I; Cl 95\% 0.13 I; 0.41 I; Table 2).

With increasing indoor temperature clothing was lighter in the total group $(-0.41$ change in clo-units per $10^{\circ} \mathrm{C}$ increase of temperature; $\left.\mathrm{Cl} 95 \%-0.46 ;-0.37\right)$ and showed a nearly linear decrease in all groups (Figure 2B). Clothing behavior was not different in adults with high or low gait speed (Table 2). Comparing results from assessments in absence of a heat wave to results assessed during a heat wave, a statistical significant difference in clothing behavior was seen in all groups with lighter clothing during a heat wave. The difference of 0.17 clounits in the total group is equivalent to leaving out a singlet (0.04) and the change from a long-sleeved (0.25) to a short-sleeved shirt (0.15) and from thick (0.05) to light socks $(0.02)$. During the heat waves there were 8 adults (10\%) with clo-unit values of 0.5 or higher. 
Table 2: Mean change of social life participation, drinking volume and clothing per $10^{\circ} \mathrm{C}$ increase of indoor temperature and mean differences of social life participation, drinking volume and clothing between heat waves and normal days

\begin{tabular}{|c|c|c|c|}
\hline Parameter, group of participants & $\mathrm{n} / \mathrm{Obs}$ & $\begin{array}{c}\text { Mean change of } \\
\text { participation/behavior } \\
\text { per } 10^{\circ} \mathrm{C} \text { increase of } \\
\text { indoor temperature } \\
\text { with }(95 \%-\mathrm{Cl})\end{array}$ & $\begin{array}{l}\text { Mean difference of } \\
\text { participation/behavior } \\
\text { between heat waves } \\
\text { and normal days* } \\
\text { with }(95 \%-\mathrm{Cl})\end{array}$ \\
\hline $\begin{array}{l}\text { WHO participation score [4-20], all } \\
\text { adults }\end{array}$ & $81 / 539$ & $-4.53(-5.32 ;-3.74)$ & $-2.77(-3.26 ;-2.29)$ \\
\hline $\begin{array}{l}\text { WHO participation score [4-20], } \\
\text { adults with initially higher gait speed }\end{array}$ & $47 / 324$ & $-3.72(-4.68 ;-2.77)$ & $-2.34(-2.93 ;-1.74)$ \\
\hline $\begin{array}{l}\text { WHO participation score }[4-20] \text {, } \\
\text { adults with initially lower gait speed }\end{array}$ & $34 / 215$ & $-5.76(-7.13 ;-4.39)$ & $-3.43(-4.26 ;-2.60)$ \\
\hline $\begin{array}{l}\text { WHO participation score [4-20], } \\
\text { adults living in garden-city/suburbs }\end{array}$ & $37 / 248$ & $-3.11(-4.19 ;-2.03)$ & $-2.00(-2.71 ;-1.29)$ \\
\hline $\begin{array}{l}\text { WHO participation score [4-20], } \\
\text { adults living in city/city-center }\end{array}$ & $44 / 291$ & $-5.87(-7.01 ;-4.73)$ & $-3.33(-3.99 ;-2.67)$ \\
\hline $\begin{array}{l}\text { Volume of drinking per day [l], all } \\
\text { adults }\end{array}$ & $81 / 539$ & $0.65(0.52 ; 0.77)$ & $0.30(0.22 ; 0.38)$ \\
\hline $\begin{array}{l}\text { Volume of drinking per day [l], adults } \\
\text { with initially higher gait speed }\end{array}$ & $47 / 324$ & $0.60(0.44 ; 0.75)$ & $0.32(0.22 ; 0.42)$ \\
\hline $\begin{array}{l}\text { Volume of drinking per day [l], adults } \\
\text { with initially lower gait speed }\end{array}$ & $34 / 215$ & $0.71(0.49 ; 0.93)$ & $0.27(0.13 ; 0.41)$ \\
\hline Clothing [clo-units], all adults & $81 / 539$ & $-0.41(-0.46 ;-0.37)$ & $-0.17(-0.20 ;-0.14)$ \\
\hline $\begin{array}{l}\text { Clothing [clo-units], adults with } \\
\text { initially higher gait speed }\end{array}$ & $47 / 324$ & $-0.40(-0.45 ;-0.35)$ & $-0.16(-0.20 ;-0.12)$ \\
\hline $\begin{array}{l}\text { Clothing [clo-units], adults with } \\
\text { initially lower gait speed }\end{array}$ & $34 / 215$ & $-0.44(-0.51 ;-0.37)$ & $-0.17(-0.22 ;-0.12)$ \\
\hline
\end{tabular}

$\mathrm{n}=$ number of subjects; Obs = number of observations; $\mathrm{Cl}=$ confidence interval ${ }^{*}$ Average temperature on normal days $=23.2($ SD 2.17) and on days during heat waves $=27.6$ (SD 1.23); better score values are underlined 
Figure 1: Association between indoor temperature and social life participation with stratification by gait speed (slow speed: $0.653 \mathrm{~m} / \mathrm{s}$ or slower for women/men with body height $<159 / 173 \mathrm{~cm}$, and $0.762 \mathrm{~m} / \mathrm{s}$ or slower for women/men with body height $\geq 159 / 173 \mathrm{~cm}$ ) $(\mathrm{A})$ or residential area (garden-city/suburb or city/city-center) (B). Indoor temperature was modelled as continuous variable and fitted in multi-level additive regression models using splines.
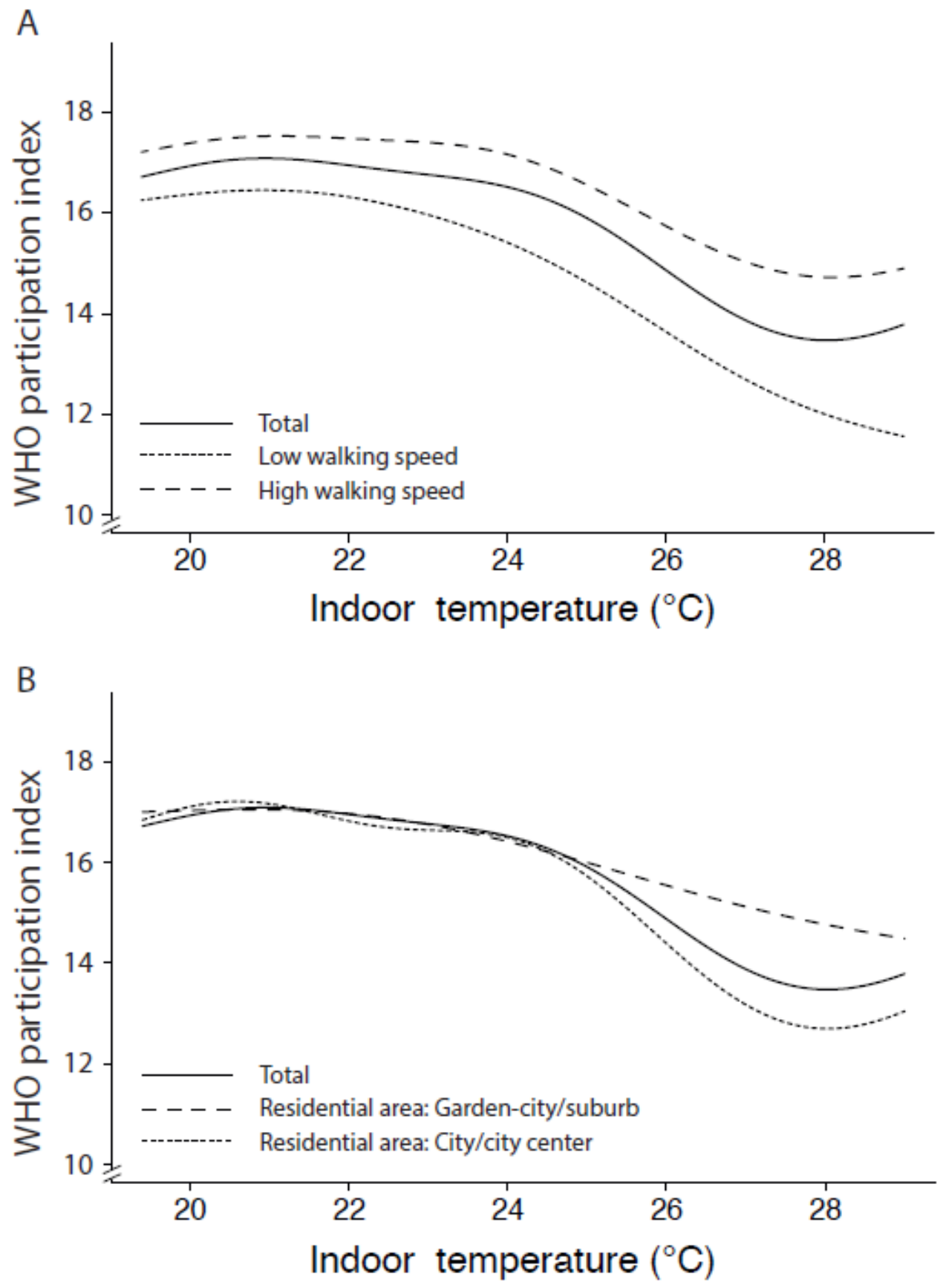
Figure 2: Association between indoor temperature and drinking volume $(A)$ as well as clothing $(B)$ with stratification by gait speed (slow speed: $0.653 \mathrm{~m} / \mathrm{s}$ or slower for women $/ \mathrm{men}$ with body height $<159 / 173 \mathrm{~cm}$, and $0.762 \mathrm{~m} / \mathrm{s}$ or slower for women/men with body height $\geq 159 / 173 \mathrm{~cm}$ ). Indoor temperature was modelled as continuous variable and fitted in multilevel additive regression models using splines.
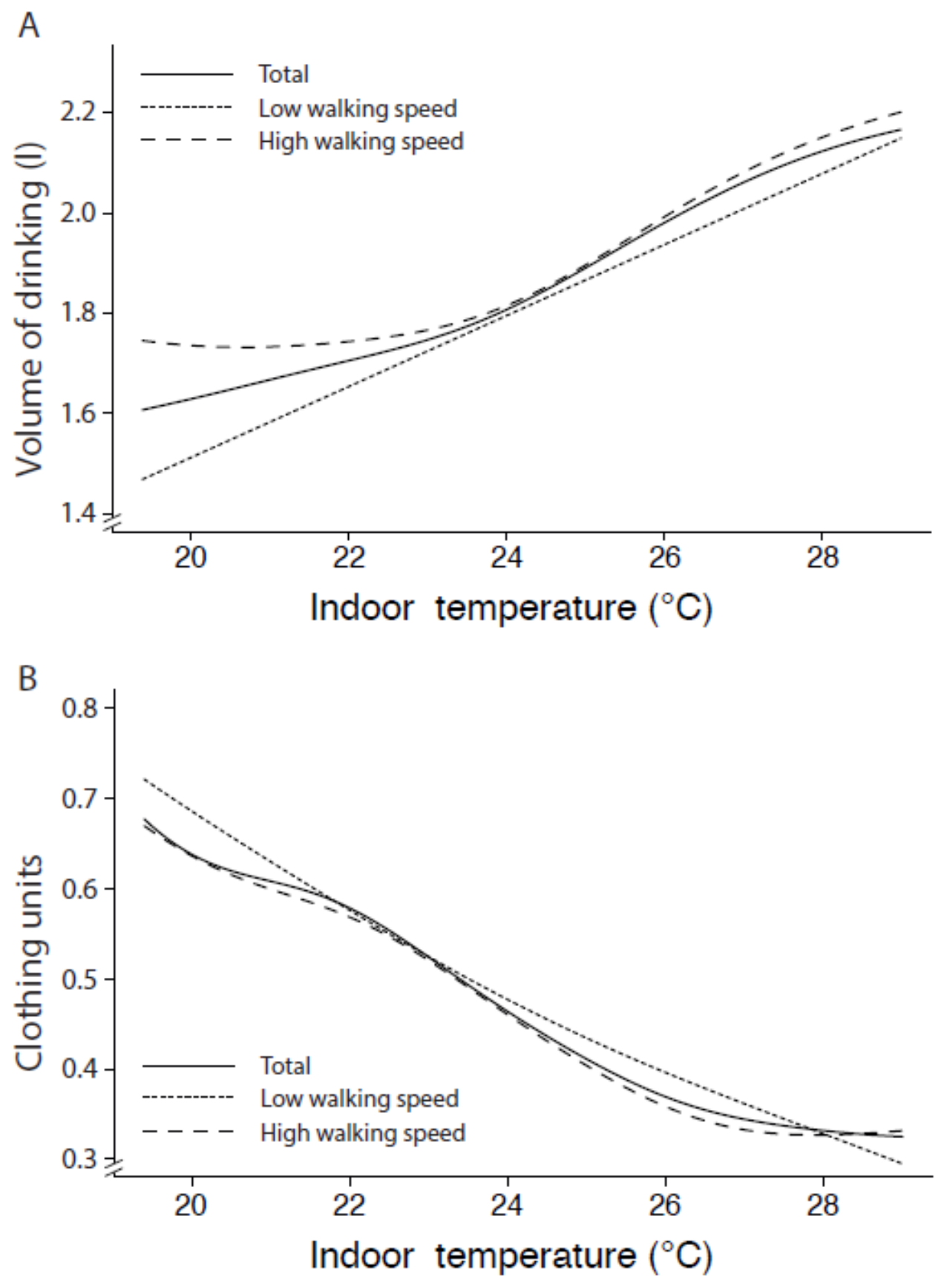
After the heat waves 79 adults were available for the structured interview on heat-adaptive behavior (Table 3). Of those, 61 adults $(77.2 \%)$ perceived the summer heat waves as stressful or very stressful. The mean value of perceived heat-stress was 3.96 (SD 1.23) on the 5-point Likert-scale.

Table 3: Adaptive behavior during heat waves of 79 available participants assessed by interview after the heat waves

\begin{tabular}{lcc}
\hline Heat-protective behavior & $\mathrm{n}$ & $\%$ \\
\hline Drinking more & 27 & 34.2 \\
Adapting clothing & 26 & 32.9 \\
Reducing activity & 69 & 87.3 \\
\hline Shading the apartment & 56 & 70.9 \\
\hline Taking a shower & 11 & 13.9 \\
Swimming in the pool & 6 & 7.6 \\
Bathing arms or feet & 14 & 17.7 \\
Letting cold air in during night time & 25 & 31.6 \\
Using a fan & 9 & 11.4 \\
Suspending wet towels & 8 & 10.1 \\
Eating light cuisine & 7 & 8.9 \\
\hline$n=$ number of subjects
\end{tabular}

$\mathrm{n}=$ number of subjects

\section{Discussion}

This study shows that high indoor temperatures and heat waves have an effect on behavior of older people. Our results are in line with other studies showing effects of extreme outdoor temperatures on social life participation (Clarke et al., 2015) and physical activity (Klenk et al., 2012).

The possibility of social life participation was reduced with increasing indoor temperature. The observed reduction is similar to the effect of other extreme weather conditions, i.e. ice 
(Clarke et al., 2015). Expecting a higher number of extreme weather situations in the near future, effective interventions and parameters to identify those most affected are needed. In our study, the effect of reduced possibility of social life participation was more prominent in the sub-group of adults with low gait speed. This might imply an advantage of a better physical fitness of older adults, which in our study was also characterized by less comorbidities. If it could be shown in future studies that improvements of physical fitness would allow high social life participation during heat, this would be a further argument for exercise interventions in general for frail older adults. In the context of health related studies, these implications are corroborated by better outcomes, such as lower falls risk (Gillespie et al., 2012), lower short-term mortality and less nursing home admission (Guralnik et al., 1994), in older adults with better physical performance. Nevertheless, it has to be mentioned that reducing general activity during heat exposure, which was reported by $87.3 \%$ of our participants, is a reasonable adaptation to heat stress.

The possibility of social life participation during heat was higher, when the residential area was located in garden-cities or suburbs. This might be explained by better microclimate with reduced temperatures in green spaces during heat (Makhelouf, A., 2013). Since the classification of residential area in our study was based on access to green spaces, our results are comparable with studies showing better self-perceived general health (Maas et al., 2006) and lower heat-related mortality (Burkart et al., 2016) associated with better access to green spaces. Future planning of new sheltered living facilities for older adults should balance between advantages and disadvantages of location. On the one hand city-center location may provide better access to shopping facilities and social life. On the other hand garden-city or suburb location may provide higher social life participation during heat waves along with other advantages of green spaces access, such as general health (Maas et al., 2006) or traffic noise reduction (Jang, Lee, Jeon, \& Kang, 2015). 
There was an adaptation of temperature-related drinking behavior in all groups with an increasing amount of drinking volume with increasing indoor temperature. Our quantitative data are in line with qualitative data of a study related to outdoor temperature where participants reported having drunk more during heat (Liu et al., 2013). Although the "optimal" amount of drinking volume cannot be concluded from our results, a volume of more than 2 liters seems to be preferable during heat stress, as demonstrated in our study at higher temperatures. External attention and care might be helpful for older adults, because the awareness of heat stress cannot be taken for granted from our results. There was an adaptation of drinking behavior to heat, but only one third reported in the structured interview after the heat waves that they had drunk more during the heat. This might indicate that drinking behavior is hard to memorize, which might be driven by the fact that older adults exhibit a decreased thirst sensation (Kenney \& Chiu, 2001). Others studies found that there was no change of behavior, even though there was awareness of extreme heat episodes, primarily due to a lack of self-perception as a vulnerable person (Bassil \& Cole, 2010). Both issues justify external attention and motivation to heat-protective behavior. In our study the general adaptation of clothing to increasing indoor temperature seemed to be adequate in all groups of older adults. Nevertheless, there were some older adults who did not change clothing behavior during heat stress. This is in line with a study where older adults underused possible adaptive behavior during heat stress (White-Newsome et al., 2011), such as changing clothes or taking showers. Again external attention and care might be helpful for these older adults.

In general, the relevance of the changes in social life participation and temperature-related behavior in our study is not clear, because there are no quantitative gold-standards. Furthermore, the results of our special cohort cannot be generalized. Environmental aspects of the buildings, such as thermal insulation or shading, were very heterogeneous for the participants' flats. Therefore, it was not possible to investigate the effect of these factors 
during heat waves. However, as we used indoor temperature the actual heat exposure was investigated, including these environmental aspects. A possible effect modification due to cognitive impairment on temperature-related behavior could not be investigated since most participants in our study were cognitively healthy. Therefore, future studies should investigate other cohorts of interest, such as cognitively impaired older adults, and should also investigate other possible effect modifiers.

\section{Conclusions}

Our study shows significant effects of indoor temperature on social life participation and temperature-related behavior. It provides a further argument for exercise interventions in older adults in general, because a better physical fitness might prevent a decrease of social life participation during heat stress. With regard to adaptation of drinking and clothing during heat stress, external attention and care might be necessary for some older adults.

\section{Acknowledgements}

This work was supported by the German State Ministry Baden-Württemberg for Environment, Climate and Energy Industries [KLIMOPASS 4500412311/23]. The sponsors did not play a role in designing the study, data collection and analysis, decision to publish and preparation of the manuscript. We thank Anja Stotz for the data collection.

\section{Author Contributions}

Ulrich Lindemann, Dawn A. Skelton and Clemens Becker designed the study. Ulrich Lindemann was responsible for data collection. Jochen Klenk and Ulrich Lindemann performed the statistical analysis of the data. All authors wrote and critically discussed the results and implications for the manuscript and approved the final version.

\section{Conflicts of Interest}

The authors declare no conflict of interest. 


\section{References}

Baccini, M., Kosatsky, T., \& Biggeri, A. (2013). Impact of summer heat on urban population mortality in Europe during the 1990s: an evaluation of years of life lost adjusted for harvesting. PLoS.One., 8(1932-6203 (Electronic)), e69638.

https://doi.org/10.1371/journal.pone.0069638

Barnett, A. G., Sans, S., Salomaa, V., Kuulasmaa, K., Dobson, A. J., \& WHO MONICA Project. (2007). The effect of temperature on systolic blood pressure. Blood Pressure Monitoring, 12(3), 195-203. https://doi.org/10.1097/MBP.0b013e3280b083f4

Bassil, K. L., \& Cole, D. C. (2010). Effectiveness of public health interventions in reducing morbidity and mortality during heat episodes: a structured review. International Journal of Environmental Research and Public Health, 7(3), 991-1001. https://doi.org/10.3390/ijerph7030991

Burkart, K., Meier, F., Schneider, A., Breitner, S., Canário, P., Alcoforado, M. J., ... Endlicher, W. (2016). Modification of Heat-Related Mortality in an Elderly Urban Population by Vegetation (Urban Green) and Proximity to Water (Urban Blue): Evidence from Lisbon, Portugal. Environmental Health Perspectives, 124(7), 927934. https://doi.org/10.1289/ehp.1409529

Clarke, P. J., Yan, T., Keusch, F., \& Gallagher, N. A. (2015). The Impact of Weather on Mobility and Participation in Older U.S. Adults. American Journal of Public Health, 105(7), 1489-1494. https://doi.org/10.2105/AJPH.2015.302582

Collins, K. J., \& Exton-Smith, A. N. (1983). 1983 Henderson Award Lecture. Thermal homeostasis in old age. Journal of the American Geriatrics Society, 31(9), 519-524.

Flouris, A. D. (2011). Functional architecture of behavioural thermoregulation. European Journal of Applied Physiology, 111(1), 1-8. https://doi.org/10.1007/s00421-010-16028 
Fried, L. P., Tangen, C. M., Walston, J., Newman, A. B., Hirsch, C., Gottdiener, J., ... McBurnie, M. A. (2001). Frailty in older adults: evidence for a phenotype. J.Gerontol.A Biol.Sci.Med.Sci., 56(1079-5006 (Print)), M146-M156.

Gillespie, L. D., Robertson, M. C., Gillespie, W. J., Sherrington, C., Gates, S., Clemson, L. M., \& Lamb, S. E. (2012). Interventions for preventing falls in older people living in the community. The Cochrane Database of Systematic Reviews, (9), CD007146. https://doi.org/10.1002/14651858.CD007146.pub3

Groll, D. L., To, T., Bombardier, C., \& Wright, J. G. (2005). The development of a comorbidity index with physical function as the outcome. J.Clin.Epidemiol., 58(0895-4356 (Print)), 595-602. https://doi.org/10.1016/j.jclinepi.2004.10.018

Guralnik, J. M., Simonsick, E. M., Ferrucci, L., Glynn, R. J., Berkman, L. F., Blazer, D. G., ... Wallace, R. B. (1994). A short physical performance battery assessing lower extremity function: association with self-reported disability and prediction of mortality and nursing home admission. J.Gerontol., 49(0022-1422 (Print)), M85-M94.

ISO 9920. (n.d.). ISO 9920:2007 - Ergonomics of the thermal environment -- Estimation of thermal insulation and water vapour resistance of a clothing ensemble. Retrieved January 12, 2015, from http://www.iso.org/iso/catalogue_detail.htm?csnumber=39257

Jang, H. S., Lee, S. C., Jeon, J. Y., \& Kang, J. (2015). Evaluation of road traffic noise abatement by vegetation treatment in a 1:10 urban scale model. The Journal of the Acoustical Society of America, 138(6), 3884-3895. https://doi.org/10.1121/1.4937769

Kaiser, R., Le Tertre, A., Schwartz, J., Gotway, C. A., Daley, W. R., \& Rubin, C. H. (2007). The effect of the 1995 heat wave in Chicago on all-cause and cause-specific mortality. American Journal of Public Health, 97 Suppl 1, S158-162. https://doi.org/10.2105/AJPH.2006.100081

Katzman, R., Brown, T., Fuld, P., Peck, A., Schechter, R., \& Schimmel, H. (1983). Validation of a short Orientation-Memory-Concentration Test of cognitive impairment. Am.J.Psychiatry, 140(0002-953X (Print)), 734-739. 
Klenk, J., Becker, C., \& Rapp, K. (2010). Heat-related mortality in residents of nursing homes. Age Ageing, 39(1468-2834 (Electronic)), 245-252. https://doi.org/10.1093/ageing/afp248

Klenk, J., Buchele, G., Rapp, K., Franke, S., \& Peter, R. (2012). Walking on sunshine: effect of weather conditions on physical activity in older people. J.Epidemiol.Community Health, 66(1470-2738 (Electronic)), 474-476. https://doi.org/10.1136/jech.2010.128090

Liu, T., Xu, Y. J., Zhang, Y. H., Yan, Q. H., Song, X. L., Xie, H. Y., ... Ma, W. J. (2013). Associations between risk perception, spontaneous adaptation behavior to heat waves and heatstroke in Guangdong province, China. BMC Public Health, 13, 913. https://doi.org/10.1186/1471-2458-13-913

Maas, J., Verheij, R. A., Groenewegen, P. P., de Vries, S., \& Spreeuwenberg, P. (2006). Green space, urbanity, and health: how strong is the relation? Journal of Epidemiology and Community Health, 60(7), 587-592. https://doi.org/10.1136/jech.2005.043125

Makhelouf, A. (2013). The contribution of urban green spaces in the regulation of the microclimate and the improvement of the air quality in cities, (3), 190-195.

Pascoe, D. D., Shanley, L. A., \& Smith, E. W. (1994). Clothing and exercise. I: Biophysics of heat transfer between the individual, clothing and environment. Sports Medicine (Auckland, N.Z.), 18(1), 38-54.

Power, M., Quinn, K., \& Schmidt, S. (2005). Development of the WHOQOL-old module. Qual.Life Res., 14(0962-9343 (Print)), 2197-2214. https://doi.org/10.1007/s11136005-7380-9

Schoon, Y., Bongers, K., Van Kempen, J., Melis, R., \& Olde Rikkert, M. (2014). Gait speed as a test for monitoring frailty in community-dwelling older people has the highest diagnostic value compared to step length and chair rise time. European Journal of Physical and Rehabilitation Medicine, 50(6), 693-701. 
Schwenk, M., Howe, C., Saleh, A., Mohler, J., Grewal, G., Armstrong, D., \& Najafi, B. (2014). Frailty and technology: a systematic review of gait analysis in those with frailty. Gerontology, 60(1), 79-89. https://doi.org/10.1159/000354211

Stadtklima Stuttgart | Klimatope | 9. Klimaanalyse-Karten (Karte-XIII, Blatt 1 bis 12). (n.d.). Retrieved November 24, 2016, from https://www.stadtklimastuttgart.de/index.php?klima_klimaatlas_9_klimatope

Steadman, R.G. (1979). The Assessment of Sultriness. Part I: A Temperature-Humidity Index Based on Human Physiology and Clothing Science, (18), 861-873. https://doi.org/10.1175/1520-0450(1979)018<0861:TAOSPI>2.0.CO;2

Sun, X., Sun, Q., Zhou, X., Li, X., Yang, M., Yu, A., \& Geng, F. (2014). Heat wave impact on mortality in Pudong New Area, China in 2013. The Science of the Total Environment, 493, 789-794. https://doi.org/10.1016/j.scitotenv.2014.06.042

Tan, J., Zheng, Y., Tang, X., Guo, C., Li, L., Song, G., ... Li, F. (2010). The urban heat island and its impact on heat waves and human health in Shanghai. International Journal of Biometeorology, 54(1), 75-84. https://doi.org/10.1007/s00484-009-0256-x

Tong, S., Ren, C., \& Becker, N. (2010). Excess deaths during the 2004 heatwave in Brisbane, Australia. International Journal of Biometeorology, 54(4), 393-400. https://doi.org/10.1007/s00484-009-0290-8

Van Loenhout, J. a. F., le Grand, A., Duijm, F., Greven, F., Vink, N. M., Hoek, G., \& Zuurbier, M. (2015). The effect of high indoor temperatures on self-perceived health of elderly persons. Environmental Research, 146, 27-34. https://doi.org/10.1016/j.envres.2015.12.012

Wardekker, J. A., de, J. A., van, B. L., Turkenburg, W. C., \& van der Sluijs, J. P. (2012). Health risks of climate change: an assessment of uncertainties and its implications for adaptation policies. Environ.Health, 11(1476-069X (Electronic)), 67. https://doi.org/10.1186/1476-069X-11-67 
White-Newsome, J. L., Sánchez, B. N., Parker, E. A., Dvonch, J. T., Zhang, Z., \& O’Neill, M. S. (2011). Assessing heat-adaptive behaviors among older, urban-dwelling adults. Maturitas, 70(1), 85-91. https://doi.org/10.1016/j.maturitas.2011.06.015 